\title{
Inhibition of cell proliferation by wortmannin in T98G cells involved induced inhibition of NF-kB transcriptional activity
}

\author{
Eduardo Parra ${ }^{1 *}$, Luís Gutierréz ${ }^{2}$ and Pedro Hecht ${ }^{1}$ \\ ${ }^{1}$ Laboratorio de Biomedicina Experimental, Escuela de Medicina, Universidad de Tarapacá. Campus Saucache, Edificio de la Escuela de Medicina, Avenida Senador \\ Luis Alberto Rossi, Arica, Chile \\ ${ }^{2}$ Facultad de Ciencias, Avenida Arturo Prat Chacón 2120, Iquique, Chile
}

\begin{abstract}
Wortmannin is an important regulator of Phosphoinositide 3-kinase (PI(3)K) signaling pathway. Changes in expression and activity of PI3-kinase and PDGF are major positive and negative regulators, respectively, of the PI3-kinase pathway, which regulates growth, survival, and proliferation. Here we have shown that cells dosed with platelet-derived-growth-factor (PDGF) and /or wortmannin, an inhibitor of PI3 kinase, proliferated at expected rates with respect to cells deprived of any additions. Cells with added platelet-derived-growth-factor (PDGF) multiplied substantially faster than naturally growing cells-some thirty percent. As anticipated, cells given only wortmannin divided over forty percent slower than cells without any dosage.

Additionally, cells transfected with a luciferase reporter carrying a consensus sequences of the nuclear factor $\mathrm{NF}-\kappa \mathrm{B}$ binding site and treated with wortmannin inhibited the activation of luciferase in T98G cells. However, this inhibition was not affected by the treatment of PDFG. Our data indicate that Wortmannin and PDGF play different role in the control of expression of Phosphoinositide 3-kinase in glioma T98G cell line.
\end{abstract}

\section{Introduction}

Wortmannin is a cell-permeable, fungal metabolite that acts as a potent, selective and irreversible inhibitor of phosphatidylinositol 3-kinase (PI3K) [1-3]. This kinase Phosphoinositide-3-kinase phosphorylates PtdIns [4,5] P2 (Phosphatidylinositol 4,5-bisphosphate) to generate phosphatidylinositol 3,4,5-trisphosphate (PIP3). PIP3 plays a key role by recruiting $\mathrm{PH}$ domain-containing proteins to the membrane, including AKT1 and PDPK1, activating signaling cascades involved in cell growth, survival, proliferation, motility and morphology $[3,4]$. Involved in immune, inflammatory and allergic responses. PI3Ks have been studied intensively since the discovery of a PI3K activity associated with two viral oncoproteins: polyoma middle $\mathrm{T}(\mathrm{mT})$ antigen and pp60v-src [5] having an important role not only in growth regulation but also in various other cellular responses $[6,7]$. In addition, following recent findings PI3K activation prevents cell death [8], that PI3K is a retrovirus-encoded oncogene [9], and that PI3K mutations increase lifespan in Caenorhabditis elegans [10]. Three mammalian PI3Ks sharing $42-58 \%$ amino acid sequence identity has been cloned and designated p110 $\alpha, \mathrm{p} 110 \beta$, and $\mathrm{p} 110 \delta$ [11]. In addition, wortmannin, also potently inhibits mammalian polo-like kinase [12]. The fungal metabolite wortmannin is a potent inhibitor of the lipid and protein kinase activities of class I PI3Ks [1]. The 50\% inhibitory concentration (IC50) values for inhibition of the isolated enzymes are all in the range of 1-10 $\mathrm{nM}$. Wortmannin irreversibly inhibits $\mathrm{p} 110 \mathrm{a}$ by reacting covalently with lysine-802 [13,14], a residue required for catalytic activity that is conserved in all phosphoinositide kinases (and in protein kinases). Wortmannin have been used extensively to study the physiological role of class I PI3Ks in various cellular responses. On the other, considerable circumstantial evidence has accumulated which strongly implicates platelet derived growth factor (PDGF) as an autocrine and/or paracrine agent in the development of numerous human tumor types [15]. PDGF and its corresponding receptor (PDGFR) have important roles in the regulation of human physiological functions [16]. It has been shown that PDGF plays a role in blood vessel formation, healing regulation and maintenance of interstitial fluid pressure $[17,18]$. The receptors of PDGF exists in two forms of strong structural homology: PDGFR $\alpha$ and PDGFR $\beta$. It is normally expressed by the cells of the supporting tissue; it plays a role in embryonic development and tissue scarring [19]. Its role in the tumorigenesis of certain cancers is currently well documented. In dermatofibrosarcoma protuberans (DFSP), PDGFR is constitutively activated inducing intracellular oncogenic signals [20]. Similarly, glioblastomas are characterized by autocrine activation of PDGFR [21]. The PDGF family consists of four protein chains that form five biologically active dimers (PDGF-AA, -AB, -BB, -CC, and -DD) [22]. Ligand binding induces dimerization and autophosphorylation of PDGFRs. Phosphorylated tyrosine residues function as docking sites for signal transduction proteins with $\mathrm{SH} 2$ domains [23]. Proteins interacting with PDGFRs

*Correspondence to: Eduardo Parra, Laboratorio de Biomedicina Experimental, Escuela de Medicina, Universidad de Tarapacá. Campus Saucache, Edificio de la Escuela de Medicina, Avenida Senador Luis Alberto Rossi, Arica, Chile, E-mail: eparraarica@gmail.com

Key words: proliferation, wortmannin, T98G cells, wortmannin NF-kB; PDGF, PI3K

Received: September 07, 2019; Accepted: September 24, 2019; Published: September 27, 2019 
include SHP2, PI 3-kinase, Src family kinases, Grb2, and Shc [24]. In addition, PDGF stimulates cell proliferation and has also been shown to be a chemoattractant for several cell types including fibroblasts, smooth muscle cells, neutrophils, and monocytes [25].

\section{Materials and methods}

\section{Cell culture}

The T98G brain tumor cell line, established from human glioblastoma, was obtained from the American Type Culture Collection (ATCC; Manassas, VA, USA). The cells were cultured in Dulbecco's modified Eagle's medium (DMEM) (Invitrogen, Carlsbad, CA, USA) supplemented with $10 \%$ fetal bovine serum (FBS), $1 \mathrm{mM}$ sodium pyruvate, $100 \mathrm{Um} / \mathrm{l}$ penicillin $\mathrm{G}, 100 \mu \mathrm{g} / \mathrm{ml}, 1$ streptomycin, $2 \mathrm{mM}$ glutamine, $1 \mathrm{mM}$ MEM non-essential amino acids and $50 \mu \mathrm{M}$ 2 -mercaptoethanol in a $5 \% \mathrm{CO}_{2}$ incubator at $37^{\circ} \mathrm{C}$. The cells were dissociated using $0.25 \%$ trypsin and $0.53 \mathrm{mM}$ EDTA solution and subcultured once in 3-5 days.

\section{Reagents}

Tris-borate-EDTA and acrylamide:bisacrylamide (29:1) were obtained from Bio-Rad (Richmond, CA, USA). Lipofectamine was obtained from Life Technologies, Inc., USA. Complete Mini EDTAfree protease inhibitor cocktail tablets and Annexin V-Flues were purchased from Roche Diagnostics GmbH (Mannheim, Germany). Phorbol 12-myristate-13-acetate (TPA) $(50 \mathrm{ng} / \mathrm{ml})$ and wortmannin $(10 \mathrm{nM})$ and PDGF $(100 \mathrm{ng} / \mathrm{ml})$ were purchased from Stratagene Inc. (La Jolla, CA, USA). Luciferase assay reagent, lysis buffer and the pGL-2 luciferase vector were obtained from Promega (Madison, WI). Recombinant human TNF- $\alpha$ was obtained from Sigma-Aldrich (St. Louis, MO).

\section{DNA synthesis assay}

DNA replication rate was measured by a $\left({ }^{3} \mathrm{H}\right)$-Thymidine incorporation assay. Cells were seeded in 96-well tissue culture plates $(1,000$ cells/well $)$ and treated with wortmannin (10 nM) or PDGF (100 $\mathrm{ng} / \mathrm{ml}$ ) (see Treatment of Cells with wortmannin and PDGF). Twenty four, 48, 72, 96 and 120 hours after treatment with wortmannin and /or PDGF $\left({ }^{3} \mathrm{H}\right)$-Thymidine $(0.5 \mathrm{mCi} /$ well $)$ was added for 3 hours. Cells were harvested with a PhD-200A cell harvested (Cambridge Technologies, Cambridge, MA), which transferred labeled lysates to paper spots. These were subsequently washed, and the amount of radioactive DNA was quantitated by scintillation counting using Biosafe II scintillation liquid.

\section{Preparation of cell lysates}

T98G human glioblastoma cells were washed once with PBS and suspended in lysis buffer (40 mM HEPES, pH 7.4, with 10\% glycerol, $1 \%$ Triton X-100, 0.5\% Nonidet P-40 (NP-40), $150 \mathrm{mM} \mathrm{NaCl}, 50 \mathrm{mM}$ $\mathrm{NaF}, 20 \mathrm{mM} \beta$-glycerol phosphate, $1 \mathrm{mM}$ EDTA, $1 \mathrm{mM}$ EGTA, 1 $\mathrm{mM}$ phenylmethylsulfonyl fluoride and $0.1 \mathrm{mM}$ vanadate) containing a protease inhibitor mixture $(1 \mathrm{mg} / \mathrm{ml}$ aprotinin, leupeptin and pepstatin). Cells lysates were cleared by centrifugation at $15,000 \mathrm{rpm}$ for $30 \mathrm{~min}$, collected and stored $-80^{\circ} \mathrm{C}$.

\section{Luciferase assay}

The NF- $\kappa B$ reporter plasmid driven by the rat prolactin minimal promoter $(-36$ to +37$)$ under the control of the two copies of the NF- $\kappa B$ binding site of the human Ig $\kappa$ light chain enhancer 5'-GGGACTTTCC3 'was kindly provided by M. Rincón and R.A. Flavell (Section of
Immunobiology, Howard Hughes Medical Institute, Yale University School of Medicine, New Haven, CT). To assay for luciferase activity, transfected cells in duplicate wells were cultured for $24 \mathrm{~h}$ before being stimulated with or without wortmannin (100 nM) or PDGF (100 ng/ $\mathrm{ml}$ ) for a defined length of time. Cells were harvested, washed twice in PBS and treated with lysis buffer (Luciferase Assay, Promega) for 5-10 $\mathrm{min}$ on ice. Lysates were spun down for $1 \mathrm{~min}$, and the total supernatants were analyzed using Luciferase Reagent (Promega) and measured in a luminometer (MicroLumat LB-96P, Berthold) for 5 sec. Background measurement was subtracted from each duplicate, and experimental values are expressed either as recorded light units, luciferase activity or as relative activity compared to extracts from unstimulated cells $[26,27]$.

\section{Results}

Cells with added wortmannin $(10 \mathrm{nM})$ divided slower than cells without any dosage (Figures 1)

As showed in figure 1 and as we anticipated, cells given only wortmannin, an inhibitor of PI3 kinase, proliferated at less expected rates with respect to cells deprived of any additions (control). The treated cells divided over twenty eight percent slower than cells without any dosage. The cells were incubated by $24,48,72,96$ and 120 hours. After treatment with wortmannin and /or PDGF $\left({ }^{3} \mathrm{H}\right)$-Thymidine $(0.5$ $\mathrm{mCi} /$ well) was added for 3 hours.

Cells with added platelet-derived-growth-factor (PDGF) multiplied substantially faster than naturally growing cells (Figures 1).

In contrast to the effect of wortmannin, T98G glioblastoma cells treated only with PDGF, proliferate at more expected rates with respect to cells deprived of any additions (Control) Using the averages on the last counting day, we see that the addition of wortmannin to cells treated with PDGF accounts for a proliferation decrease of about 15888 (82876-66987), a number which also equals the difference in averages between control cells (58654) and cells dosed with wortmannin only (41678). From this data it can be inferred that wortmannin inhibits cells boosted with PDGF by the same amount as it inhibits control cells.

Wortmannin treatment causes inhibition of the Luc-reporterNF-kB (Luc-2x GGGACTTTCC) in TPA activated T98G cells (Figure 2)

In order to test whether wortmannin is an effective inhibitor of NF$\mathrm{kB}$ transcriptional activity in T98G cells, transient transfection assay was performed. One Luciferase- base reporter constructs regulated by binding of NF- $\mathrm{kB}$ transcription complex to multiple copies of classical NF- $\kappa$ B site (Luc-2x-GGGACTTTCC) was examined: pGL-2-Luc- $\kappa B$ ). Thus, specific inhibition of the activated PI3K pathway is predicted to inhibit the NF- $\kappa \mathrm{B}$ dependent reporter. The reporter showed enhanced expression up to 10 fold and 7 respectively when activated with TPA an activator of NF- $\kappa B$ or with PDGF. As control, parallel transfection was carried out with a control reporter vector, pGL-2 Luc, without $\kappa B$. Cells treated with wortmannin and transfected with de reporter vector Luc$\mathrm{NF}-\kappa \mathrm{B}$, but not the untreated cells, led to a substantial inhibition (aprox. $75 \%$ ) of the reporter activated by TPA in the transiently transfected NF- $\kappa \mathrm{B}$ in T98G glioblastoma cells (Figure 2). The observation that expression of wortmannin inhibit TPA activated NF- $\kappa B-L u c$ reporter construct is consistent with the role of NF- $\mathrm{BB}$-dependent system in T98G cells. However, cells treated with PDGF led to a substantial increase in luciferase reporter gene expression (Figure 2). 
Figure 1 and 2, Parra et al., 2019

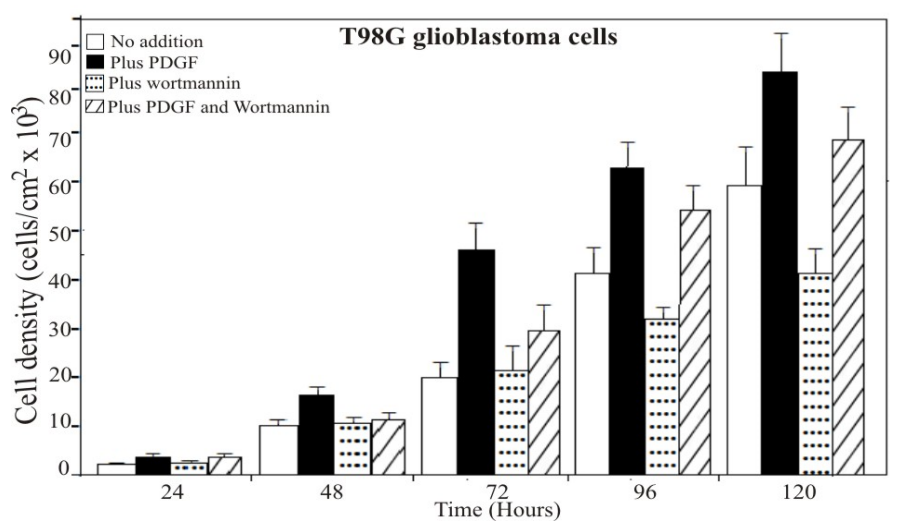

Figure 1. T98G cells dosed with PDGF or wortmannin proliferate at expected rates with respect to the control cells. T98G cells were plated in multiwell tissue culture plates at $25 \times 103$ cells in medium containing $10 \%$ FCS and counted (Coulter counter) on the indicated days in triplicate. The average values are plotted here to define the growth of the cells. The maximum proliferation is plotted as a function of PDGF to increase cell growth or proliferation. The minimum proliferation of the cells is plotted as a function of wortmannin to inhibit or delayed cell growth. One of three experiments is shown

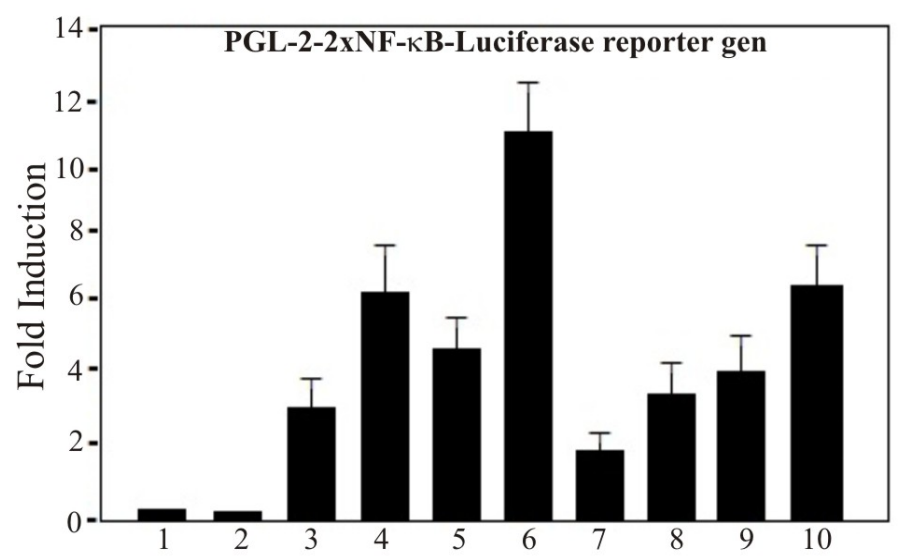

Figure 2. PDGF and Wortmannin Treatment of T98G cells. T98G cells were seeded in 24-well tissue culture plates at a density of $5 \times 10^{3} \mathrm{cells} / \mathrm{cm}^{2}$ and transfected next day with $25 \mathrm{ng} / \mathrm{well}$ of reporter gen Luciferase (pGL-2-Luc) carrying two repeats of the consensus DNA sequence for the NF-kB binding site (Luc-2x-GGGACTTTCC) or empty vector control. Transfection and analysis of data were carried out as described in Materials and Methods. Lane: Control cells; Lane 2: Cells treated with PDGF; Lane 3: Cells treated with wortmannin; Lane 4: Cells treated with both, PDGF and Wortmannin. One of three experiments is shown

From this data it can be inferred that wortmannin inhibits cells boosted with PDGF by the same amount as it inhibits control cells.

\section{Discussion}

In the present study we investigated the effect of PDGF and wortmannin in T98G glioblastoma human cells. PDGF is a multifunctional peptide, with a biologically active form that is a dimer composed of A, B, C, and D chains. The activity of PDGF depends on the dimer formed: $\mathrm{AA}, \mathrm{AB}, \mathrm{BB}, \mathrm{CC}$, or $\mathrm{DD}(19,20,21)$. On the other hand, Wortmannin, a steroid metabolite of the fungi Penicillium funiculosum, Talaromyces wortmanni, is a non-specific, covalent inhibitor of phosphoinositide 3-kinases (PI3Ks) $(1,2)$. In summary, in this study we showed that cells treated with platelet-derivedgrowth-factor (PDGF) and /or wortmannin, an inhibitor of PI3 kinase proliferated at expected rates with respect to cells control (deprived of any additions). Cells with added platelet-derived-growth-factor (PDGF) multiplied substantially faster than control and wortmannin treated growing cells, some thirty percent. As anticipated, cells given only wortmannin divided slower than cells without any dosage. A more revealing comparison is that between the case of only PDGF added to the case of PDGF and wortmannin added. Using the averages on the last counting day, we showed that the addition of wortmannin to cells treated with PDGF accounts for a proliferation decrease of about 15888 (82876-66987), a number which also equals the difference in averages between control cells (58654) and cells dosed with wortmannin only (41678). From this data it can be inferred that wortmannin inhibits cells boosted with PDGF by the same amount as it inhibits control cells. PDGF, then increases cell growth by means of the same pathway which wortmannin inhibits the basal pathway, likely through downregulation of PI3K signaling and NF-kappa B protein expression.

The observation that expression of wortmannin inhibit TPA activated NF- $\kappa \mathrm{B}$-Luc reporter construct is consistent with the role of NF- $\kappa B$-dependent system in T98G cells. The assay showed that cells treated with PDGF led to a substantial increase in luciferase reporter gene expression while wortmannin decrease de expression of the Luciferase reporter gene. From this data it can be inferred that wortmannin inhibits cells boosted with PDGF by the same amount as it inhibits control cells.

\section{Acknowledgements}

We thank Dra. M. Rincón and R.A. Flavell (Section of Immunobiology, Howard Hughes Medical Institute, Yale University School of Medicine, New Haven, CT). for providing the reporter gen vector carrying the $2 \mathrm{x} N F-\kappa B$ consensus sequence. This work was supported by grants from Universidad de Tarapacá. Project-UTAMayor, No UTA-7701-2018.

\section{References}

1. Arcaro A, Wymann MP (1993) Wortmannin is a potent phosphatidylinositol 3-kinase inhibitor: the role of phosphatidylinositol 3,4,5-trisphosphate in neutrophil responses. Biochem J 296: 297-301. [Crossref]

2. Fukao T, Koyasu S (2003) PI3K and negative regulation of TLR signaling. Trends Immunol 24: 358-363. [Crossref]

3. Hazeki K, Kinoshita S, Matsumura T, Nigorikawa K, Kubo H, et al. (2006) Opposite effects of Wortmannin and 2-(4-Morpholinyl)-8-phenyl-1(4H)-benzopyran-4-one Hydrochloride on toll- like receptor-mediated nitric oxide production: Negative regulation of nuclear factor- $\mathrm{\kappa B}$ by phosphoinositide 3-kinase. Mol Pharmacol 69: 1717-1724. [Crossref]

4. Miao B, Skidan I, Yang J, Lugovskoy A, Degterevv A, et al. (2010) Small molecule inhibition of phosphatidylinositol-3,4,5-triphosphate (PIP3) binding to pleckstrin homology domains. Proc Natl Acad Sci USA 107: 20126-20131. [Crossref]

5. Vogt PK, Hart JR, Gymnopoulos M, Jiang H, Kang S, et al. (2011) Phosphatidylinositol 3-kinase (PI3K): The Oncoprotein. Curr Top Microbiol Immunol 347: 79-104. [Crossref]

6. Blommaart EF, Krause U, Schellens JP, Vreeling-Sindelárová H, Meijer AJ (1997) The phosphatidylinositol 3-kinase inhibitors wortmannin and LY294002 inhibit autophagy in isolated rat hepatocytes. Eur J Biochem 243: 240-246. [Crossref]

7. Alcazar I, Marques M, Kumar A, Hirsch E, Wymann M, et al. (2007) Phosphoinositide 3-kinase gamma participates in T cell receptor-induced T cell activation. $J$ Exp Med 204: 2977-2987. [Crossref]

8. Jadali A, Kwan KY (2016) Activation of PI3K signaling prevents aminoglycosideinduced hair cell death in the murine cochlea. Biology Open 5: 698-708. [Crossref]

9. Hutti JE, Pfefferle AD, Russell SC, Sircar M, Perou CM, et al. (2012) Oncogenic PI3K mutations lead to NF-kB-dependent cytokine. Expression following growth factor deprivation. Cancer Res 72: 3260-3269. [Crossref]

10. Ayyadevara S, Tazearslan C, Bharill P, Alla R, Siegel E, et al. (2009) Caenorhabditis elegans PI3K mutants reveal novel genes underlying exceptional stress resistance and lifespan. Aging Cell 8: 706-725. [Crossref] 
11. Yu X, Long YC, Shen HM (2015) Differential regulatory functions of three classes of phosphatidylinositol and phosphoinositide 3-kinases in autophagy. Autophagy 11: 1711-1728. [Crossref]

12. Liu Y, Shreder KR, Gai W, Corral S, Ferris DK, et al. (2005) Wortmannin, a widely used phosphoinositide 3-kinase inhibitor, also potently inhibits mammalian polo-like kinase. Chem Biol 12: 99-107. [Crossref]

13. Shugg RP, Thomson A, Tanabe N, Kashishian A, Steiner BH, et al. (2013) Effects of isoform-selective phosphatidylinositol 3-kinase inhibitors on osteoclasts: actions on cytoskeletal organization, survival, and resorption. J Biol Chem 288: 35346-35357. [Crossref]

14. Chang HW, Aoki M, Fruman D, Auger KR, Bellacosa A (1997) The phosphatidylinositol 3-kinase inhibitor, PX-866, is a potent inhibitor of cancer cell motility and growth in three-dimensional cultures. Science 276: 1848-1850.

15. Hiles ID, Otsu M, Volinia S, Fry MJ, Gout I (1993) Phosphatidylinositol 3-kinase: structure and expression of the $110 \mathrm{kd}$ catalytic subunit. Cell 70: 419-429. [Crossref]

16. Wymann MP, Bulgarelli-Leva G, Zvelebil MJ, Pirola L, Vanhaesebroeck B (1996) Wortmannin inhibits PI3K activity by binding to a conserved lysine residues in the ATP-binding site of the enzyme. Mol Cell Biol 16: 1722-1733.

17. Raica M, Cimpean AM (2010) Platelet-derived growth factor (PDGF)/PDGF receptors (PDGFR) axis as target for antitumor and antiangiogenic therapy. Pharmaceuticals (Basel) 3: 572-599. [Crossref]

18. Berk BC, Alexander RW, Brock TA, Gimbrone MA Jr, Webb RC (1986) Vasoconstriction: A new activity for platelet-derived growth factor. Science 232: 8790. [Crossref]

19. Heldin CH, Lennartsson J (2013) Structural and functional properties of plateletderived growth factor and stem cell factor receptors. Cold Spring Harb Perspect Biol 5: a009100. [Crossref]
20. Capdeville R, Buchdunger E, Zimmermann J, Matter A (2002) Glivec (STI571, imatinib), a rationally developed, targeted anticancer drug. Nat Rev Drug Discov 1: 493-502. [Crossref]

21. Shimizu A, O’Brien KP, Sjöblom T, Pietras K, Buchdunger E, et al. (1999) The dermatofibrosarcoma protuberans-associated collagen type Ialpha1/platelet-derived growth factor (PDGF) B-chain fusion gene generates a transforming protein that is processed to functional PDGF-BB. Cancer Res 59: 3719-3723. [Crossref]

22. Nistér M, Claesson-Welsh L, Eriksson A, Heldin CH, Westermark B (1991) Differential expression of platelet-derived growth factor receptors in human malignant glioma cell lines. J Biol Chem 266: 16755-16763. [Crossref]

23. Fredriksson L, Li H, Eriksson U (2004) The PDGF family: Four gene products form five dimeric isoforms. Cytokine Growth Factor Rev 15: 197-204. [Crossref]

24. Bonita DP, Miyake S, Lupher Jr ML, Langdon WY, Band H (1997) Phosphotyrosine binding domain-dependent upregulation of the platelet-derived growth factor receptor alpha signaling cascade by transforming mutants of Cbl: implications for Cbl's function and oncogenicity. Mol Cell Biol 17: 4597-4610. [Crossref]

25. Clunn GF, Refson JS, Lymn JS, Hughes AD (1997) Platelet-derived growth factor beta-receptors can both promote and inhibit chemotaxis in human vascular smooth muscle cells. Arterioscler Thromb Vasc Biol 17: 2622-2629. [Crossref]

26. Parra E, McGuire K, Hedlund G, Dohlsten M (1998) Overexpression of p65 and c-Jun substitutes for B7-1 costimulation by targeting the CD28RE within the IL-2 promoter. $J$ Immunol 160: 5374-5381. [Crossref]

27. Mahoney DJ, Cheung HH, Mrad RL, Plenchette S, Simard C, et al. (2008) Both cIAP1 and cIAP2 regulate TNFalpha-mediated NF-kappaB activation. Proc Natl Acad Sci USA 105: 11778-11783. [Crossref]

Copyright: (C2019 Parra E. This is an open-access article distributed under the terms of the Creative Commons Attribution License, which permits unrestricted use, distribution, and reproduction in any medium, provided the original author and source are credited. 